\title{
Markov Process in Varying Value in Production by Machinery with Two Components
}

\author{
C. Mohan, P.Selvaraju ,S.Shanmugan
}

\begin{abstract}
In this paper production and availability of machinery for production are considered. Here a machinery of production with two components is considered and that production is full when the machinery is working with both the components functioning well. But there is a chance that the whole machinery may dysfunction because of failure of both components in which case the production comes to a standstill and it is worst crisis. The other possibility is that one of the components may fail but still the machine continues functioning but with less efficiency. The production may continue and if the other component also fails the production completely stops and the situation is critical. When the machine is in one component failure, the failed part may be a repaired and machine can be made to work with full efficiency. But when both components fail, should be renewed as a package and then the production should start. Under such conditions found the steady state probabilities and the rate of crisis and the expected cost of production.

Keywords: Markov Process, Two Components, Variations in Production. Mathematics Subject Classification: 90B05.
\end{abstract}

\section{INTRODUCTION}

Several researchers studied single commodity inventory systems of $(\mathrm{s}, \mathrm{S})$ type. Here use a new concept of which has been introduced as Setting the Clock Back to Zero (SCBZ) by Raja Rao [12] and studied by K. Usha, Eswari Prem and Ramanarayanan.R [14] to Time to vital Organs failure of Gestational Diabetic Person. S. Murthy and Ramanarayanan.R [6] studied one ordering and two ordering levels inventory system with SCBZ property. Arrow, Karlin and Scart [1] first analyzed such inventory system. Bulk demand models were treated by Ramanarayanan.R and M.J. Jacob [13]. Murthy and Ramanarayanan [7, 8, 9, 10, 11] considered several (s, S) inventory system. Wu and Liang-yuh ouyang [4] studied (Q, R, L) inventory model with defective items. Bhattacharya S.K., R.Biswas, M.M.Ghosh, P. Banerjee [2] A study of risk factors of diabetes mellitus. Daniel.J.K and Ramanarayanan. $\mathrm{R}$ [3] An (S, s) inventory system with rest periods to the server. Production depends on machineries and manpower. Production crisis because of machinery has been dealt in paper of C.Mohan, et. al., [5] and the crisis situation that arise because manpower has been brought out in the paper of C.Mohan, et. al., [6].

This paper deals with the production that is likely to suffer because machinery breaks down. It is assumed that the efficient

Manuscript published on 30 August 2019.

*Correspondence Author(s)

C. Mohan Vel Tech Hightech Dr.Rangarajan Dr.Sakunthala Engineering College, Chennai,India.

P.Selvaraju Vel Tech Multitech Dr Rangarajan Dr Sakunthala Engineering College,Chennai, India,

S.Shanmugan KL University,Vijayawada,AP

(C) The Authors. Published by Blue Eyes Intelligence Engineering and Sciences Publication (BEIESP). This is an open access article under the CC-BY-NC-ND license http://creativecommons.org/licenses/by-nc-nd/4.0/ function of machinery depends on its two components but can work with lesser capacity if it has to work with one of its components under repair. The machinery stops production completely if both components fail and situation is very critical. It can be brought back to full production only when both components are replaced as a package. The steady state probabilities are determined, rate of crisis is calculated and also the expected cost of production is determined.

\section{ASSEMPTIONS}

Two components which are likely to fail in machinery are considered. The production will be full when both the components are in good condition. There is always a chance for the components to fail which will stop the production.

1. Let $\mathrm{T}$ be the time during which both components of the machinery function well and let the rate of failure be $\lambda_{1}$ and follows exponential distribution.

2. Let $T$ ' be the time during which both components of the machinery function well and let the rate of failure one of the components be $\lambda_{2}$ and it follows exponential distribution

3. Let T" be the time during which second component of the machinery function and let the rate of failure of second component be $\lambda_{3}$ and follows exponential distribution.

4. Let $\mathrm{R}$ be time during which one of the components work and the rate of repair is $\mu$ and it

follows exponential distribution.

5. Let $\mathrm{R}^{\prime}$ be time required to renew the components as a package (both the components failed at a time and requires a package replacement) for full working of machinery and is exponentially distributed with $\mathrm{k} \mu$.

The rate at which production(business) changes from shortage to full follows exponential distribution with parameter $\mathrm{b}$ and from full to shortage also follows exponential distribution with parameter

\section{SYSTEM PROCESS}

Process $\{X(t)=i, i=2,1,0\}$, denotes the stochastic process of components failure, $i=2$ means both the components are in working condition, $i=1$ means one of the component works and $i=0$ means both components have failed and components have to be replaced as a package. Process $\{Y(t)=j, j=0,1\}, j=0$ means that production is in shortage or nil and $j=1$ means production is full $\{X(t), Y(t)\}$ describing the state of the system is a continuous time chain and $X(t)$ and $Y(t)$ are independent. The state space given by :

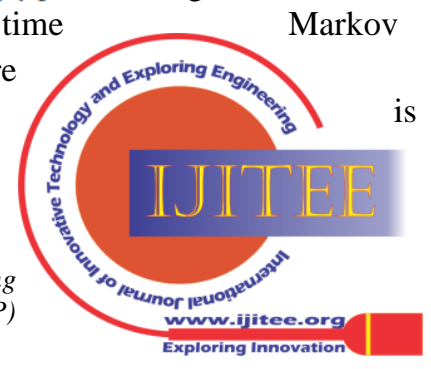




\section{Markov Process in Varying Value in Production by Machinery with Two Components}

(1)

$$
S=\left\{\frac{(i, j)}{i}=2,1,0 \text { and } j=0,1\right\}
$$

So there are totally six different states given by the matrix A :

\begin{tabular}{|c|c|c|c|c|c|c|}
\hline$(\mathrm{i}, \mathrm{j})$ & $(2,0)$ & $(2,1)$ & $(1,0)$ & $(1,1)$ & $(0,0)$ & $(0,1)$ \\
\hline$(2,0)$ & $€_{1}$ & $\mathrm{~b}$ & $\lambda_{2}$ & 0 & $\lambda_{1}$ & 0 \\
\hline$(2,1)$ & $\mathrm{A}$ & $€_{2}$ & 0 & $\lambda_{2}$ & 0 & $\lambda_{1}$ \\
\hline$(1,0)$ & $\mu$ & 0 & $€_{3}$ & $\mathrm{~B}$ & $\lambda_{3}$ & 0 \\
\hline$(1,1)$ & 0 & $\mu$ & $\mathrm{a}$ & $€_{4}$ & 0 & $\lambda_{3}$ \\
\hline$(0,0)$ & $\mathrm{k} \mu$ & 0 & 0 & 0 & $€_{5}$ & $\mathrm{~b}$ \\
\hline$(0,1)$ & 0 & $\mathrm{k} \mu$ & 0 & 0 & $\mathrm{~A}$ & $€_{6}$ \\
\hline
\end{tabular}

$$
\begin{array}{lr}
\text { Where } €_{1}=-\left(\lambda_{2}+\lambda_{1}+\mathrm{b}\right), & €_{2}=-\left(\lambda_{2}+\lambda_{1}+\mathrm{a}\right), \\
€_{3}=-\left(\lambda_{3}+\mu+\mathrm{b}\right), & €_{5}=-(\mathrm{k} \mu+\mathrm{b}) \\
€_{4}=-\left(\lambda_{3}+\mu+\mathrm{a}\right) &
\end{array}
$$

It can be seen from the matrix A that the state space is irreducible.

If $\pi_{(\mathrm{i}, \mathrm{j})}$ denotes the limiting distribution, then

$$
\Pi_{(\mathrm{ij})}=
$$

$$
\lim _{t \rightarrow \infty} \operatorname{Pr}[(X(t), Y(t))=(i, j), i, j \in S]
$$

Let $\pi=\left[\pi_{(20)}, \pi_{(21)}, \pi_{(10)}\right.$,

$$
\left.\pi_{(11)}, \pi_{(00)}, \pi_{(01)}\right]
$$

The limiting distribution exists and satisfies the equations: $\pi \bar{A}=0$ and

$$
\begin{aligned}
\sum \sum \pi_{(i j)} & =1, \mathrm{i}=0,1,2 . \text { and } \mathrm{j}=0,1 . \\
\pi_{(00)} & =\frac{1}{1+\frac{\mathrm{k \mu}\left[\lambda_{2}+\lambda_{3}+\mu\right]}{Q}} \times \frac{a}{a+b},
\end{aligned}
$$

Where $Q=\mu \lambda_{1}+\lambda_{3}\left(\lambda_{1}+\lambda_{2}\right)$

$$
\begin{aligned}
& \pi_{(01)}=\frac{1}{1+\frac{1}{\frac{k \mu}{Q}\left[\lambda_{2}+\lambda_{3}+\mu\right]}} \times \frac{b}{a+b}, \quad \pi_{(10)}= \\
& \frac{1}{1+\frac{\mathrm{k \mu}}{\frac{Q}{Q}\left[\lambda_{2}+\lambda_{3}+\mu\right]}} \times \frac{\mathrm{k} \mu \lambda_{2}}{Q} \frac{a}{(a+b)} \\
& \pi_{(11)}=\frac{1}{1+\frac{1}{\frac{\mathrm{k} \mu}{Q}\left[\lambda_{2}+\lambda_{3}+\mu\right]}} \times \frac{\mathrm{k} \mu \lambda_{2}}{Q} \frac{b}{(a+b)}, \pi_{(20)} \\
& =\frac{1}{1+\frac{\mathrm{k \mu}}{\frac{1}{Q}\left[\lambda_{2}+\lambda_{3}+\mu\right]}} \times \frac{\mathrm{k} \mu\left(\lambda_{3}+\mu\right)}{Q} \frac{a}{(a+b)}
\end{aligned}
$$

using (4) and the values are given in the following table:

$$
\pi_{(21)}=\frac{1}{1+\frac{1}{\frac{\mathrm{k \mu}}{Q}\left[\lambda_{2}+\lambda_{3}+\mu\right]}} \times \frac{\mathrm{k} \mu\left(\lambda_{3}+\mu\right)}{Q} \frac{b}{(a+b)}
$$

The crisis in production comes when only one component functions and full production is going on or full production goes on but the machine does not function because both the components have failed. From the above figure one can observe that Crisis is given by

Crisis in production in the interval of time $t$ and $t+$ $\Delta t$ is given by

$\mathrm{P}[$ Crisis $(\mathrm{t} \mathrm{t}+\Delta t)]=$

$$
\mathrm{P}[\mathrm{X}(\mathrm{t} \mathrm{t}+\Delta t)=0, \mathrm{Y}(\mathrm{t} \mathrm{t}+\Delta t)=1 / \mathrm{X}(\mathrm{t})=2, \mathrm{Y}(
$$

$\mathrm{t})=1] \times[\mathrm{X}(\mathrm{t})=2, \mathrm{Y}(\mathrm{t})=1]$

$$
+\mathrm{P}[\mathrm{X}(\mathrm{tt}+\Delta t)=0, \mathrm{Y}(\mathrm{tt}+\Delta t)=1 / \mathrm{X}(\mathrm{t})=1, \mathrm{Y}(
$$

$\mathrm{t})=1] \mathrm{x}[\mathrm{X}(\mathrm{t})=1, \mathrm{Y}(\mathrm{t})=1]+$

$\mathrm{P}[\mathrm{X}(\mathrm{t} \mathrm{t}+\Delta t)=1, \mathrm{Y}(\mathrm{t} \mathrm{t}+\Delta t)=1 / \mathrm{X}(\mathrm{t})=2, \mathrm{Y}(\mathrm{t})=1] \mathrm{x}$

$[\mathrm{X}(\mathrm{t})=2, \mathrm{Y}(\mathrm{t})=1]+\mathrm{O} \Delta \mathrm{t}$

Taking limit as $\Delta \mathrm{t} \rightarrow 0$ we get,

$$
\mathrm{C}_{\mathrm{t}}=\lambda_{1} \mathrm{P}_{(21)}(\mathrm{t})+\lambda_{3} \mathrm{P}_{(11)}(\mathrm{t})+\lambda_{2} \mathrm{P}_{(21)}(\mathrm{t})
$$

when $\mathrm{t} \rightarrow \infty$, we get the rate of crisis as $\mathrm{C}_{\infty}$ and

$$
\mathrm{C}_{\infty}=\lambda_{1} \pi_{(21)}+\lambda_{3} \pi_{(11)}+\lambda_{2} \pi_{(21)}
$$

Using steady state probabilities, we get:,

$$
\begin{aligned}
& \mathrm{C}_{\infty}=\mathrm{Yx} \frac{\mathrm{k} \mu}{Q} \frac{b}{(a+b)}\left[\lambda_{1} \lambda_{3}+2 \lambda_{2} \lambda_{3}+\mu \lambda_{1+\mu} \lambda_{2}\right], \\
& \text { Where } Y=\frac{1}{1+\frac{1}{\frac{k \mu}{Q}\left[\lambda_{2}+\lambda_{3}+\mu\right]}} \text {, }
\end{aligned}
$$

$\mathrm{Q}=\mu \lambda_{1}+\lambda_{3}\left(\lambda_{1}+\lambda_{2}\right)$

By taking $\lambda_{1}=8, \quad \lambda_{2}=10, \lambda 3=12, \quad \mu=2, k=5 ; a=$ $10, \mathrm{~b}=12$,

The following steady state probabilities are derived:

\begin{tabular}{|l|l|l|}
\hline S.No & $\begin{array}{l}\text { Steady } \\
\text { state }\end{array}$ & Probability \\
\hline 1 & $\pi_{00}$ & 0.2234 \\
\hline 2 & $\pi_{01}$ & 0.2681 \\
\hline 3 & $\pi_{10}$ & 0.0963 \\
\hline 4 & $\pi_{11}$ & 0.1155 \\
\hline 5 & $\pi_{20}$ & 0.1348 \\
\hline 6 & $\pi_{21}$ & 0.1619 \\
\hline & TOTAL & 1.0000 \\
\hline
\end{tabular}

By taking $\mathrm{k}=5,8,12,16$ and 20, determine the rate of crisis

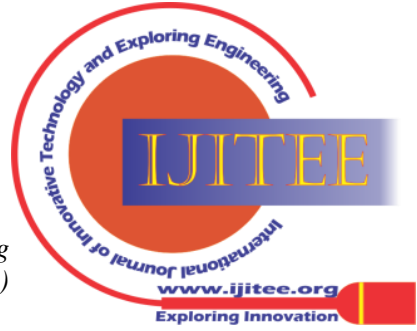




\begin{tabular}{|c|c|}
\hline $\mathrm{k}$ & $\mathrm{C}_{\infty}$ \\
\hline 5 & 4.30 \\
\hline 8 & 5.27 \\
\hline 12 & 6.03 \\
\hline 16 & 6.49 \\
\hline 20 & 6.81 \\
\hline
\end{tabular}

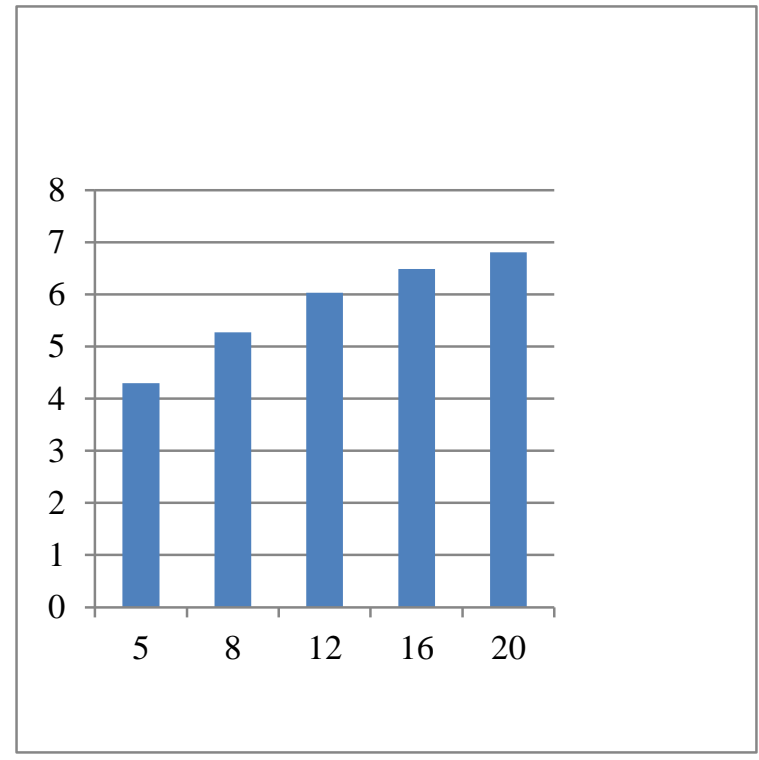

Find that as $\mathrm{k}$ increases $\mathrm{k} \mu$ will increase which results in repair/ replacing time increasing consequently crisis rate increases. The steady cost is determined using the formula

$$
\mathrm{C}_{\mathrm{ij}}=\pi_{i j}\left[\mathrm{C}_{\mathrm{i}}+\mathrm{C}_{\mathrm{j}}\right], \quad \mathrm{i}=0,1,2 \text {. and } \mathrm{j}=0 \text { and } 1 .
$$

The steady state costs in different states are determined by taking the values

$\mathrm{C}_{2}=2, \mathrm{C}_{0}=1 ; \mathrm{C}_{2}=2, \mathrm{C}_{1}=4 ; \mathrm{C}_{1}=3, \mathrm{C}_{0}=1 ; \mathrm{C}_{1}=3, \mathrm{C}_{1}=5 ; \mathrm{C}_{0}$ $=5, \mathrm{C}_{0}=1 ; \mathrm{C}_{0}=5, \mathrm{C}_{1}=8$ using (5), we get,
From the above table observe that the cost of state is high when both components are under repair and the situation is for full production (1), as such machine fails to work and so replacement cost is there and also a big cost has to be incurred because production has to be carried out whatever may be. The least cost occurs at the state when machine perfectly works (both the components are in full working condition) so no machine cost at the same time no production cost as production is nil.

\begin{tabular}{|c|c|c|}
\hline S.No & $\begin{array}{c}\text { Steady } \\
\text { state } \\
\text { probability }\end{array}$ & $\begin{array}{c}\text { Cost } \\
\text { of } \\
\text { state }\end{array}$ \\
\hline 1 & $\pi_{00}$ & 1.3404 \\
\hline 2 & $\pi_{01}$ & 3.4853 \\
\hline 3 & $\pi_{10}$ & 0.3852 \\
\hline 4 & $\pi_{11}$ & 0.9240 \\
\hline 5 & $\pi_{20}$ & 0.4044 \\
\hline 6 & $\pi_{21}$ & 0.9780 \\
\hline & TOTAL & 7.5101 \\
\hline
\end{tabular}

III. CONCLUSION

In this found pair of wheels at the back side of heavy vehicles on both sides to withstand the heavy loads. When one of the wheels develop a problem still the vehicle may run but with strain and for a short distance only and if both wheels fail both of them have to be replaced for full efficiency. this can apply the model for kidney functioning, if one kidney fails, person may live with the other kidney, if both develop problem then it may lead to dialysis and in the worst condition kidney transplantation. This may be extent to four wheel vehicle.

\section{REFERENCES}

1. K. Arrow, S. Karlin and H. Scarf, "Studies in the Mathematical Theory of Inventory and Production", Standard University Press, Standard, California, 1958

2. S.K. Bhattacharya, R. Biswas, M.M. Ghosh and P. Banerjee, "A study of risk factors of diabetes mellitus”, Indian. J Community Med., 18, (1993)

3. J.K. Daniel and R. Ramanarayanan, "An $(S, s)$ inventory system with rest periods to the Server", Naval Research Logistics, 35 (1988), 119-123.

4. Kun-Shan Wu, Liang-Yuh Ouyang, “(Q, r, L) Inventory model with defective items", Computers \& Industrial Engineering, Vol. 39, Iss 1-2, (2001), 173-185.

5. C.Mohan, P.Selvaraju, "Crisis rate of Analysis of Manufacturing concern subjected to Failure Of Machines and Production", I. J. of Pure and App. Maths.Vol116, NO.23 2017 87-92. 


\section{Markov Process in Varying Value in Production by Machinery with Two Components}

6. C.Mohan, P.Selvaraju, "The Analysis of Manpower Affecting Marketing with the Introduction detection location phase for review and Recruitment", Int. J. of Pure and Applied Mathematics.Volume116, NO.23, 2017, 93 - 97

7. S. Murthy and R. Ramanarayan, "One ordering and two ordering levels Inventory systems units with SCBZ lead times", Int. J. of Pure and Appl. Maths, 47(3) (2008), 427-447.

8. S. Murthy and R. Ramanarayanan, "Two ordering levels inventory system with different lead times and rest time to the server", Inter. J. of Applied Math., 21(2) (2008), 265-280.

9. S. Murthy and R. Ramanarayanan, "Two (s, S) inventories with perishable units", The Journal of Modern Mathematics and Statistics, 2(3) (2008), 102-108.

10. S. Murthy and R. Ramanarayan, "Inventory system exposed to Calamity with SCBZ arrival property", The Journal of Modern Mathematics and Statistics, 2(3) (2008), 109-119.

11. S. Parvathi, R. Ramanarayanan and S. Srinivasaragavan, "General Analysis Of Two Products Inventory System With Seasonal Production And Sales", IJPAM, Vol. 87 No. 2 2013, 195-204

12. B. Raja Rao, "Life expectancy for setting the clock back to zero property", Mathematical Biosciences, (1998), 251-271.

13. R. Ramanarayanan and M.J. Jacob, General analysis of (S, s) inventory systems with random lead time and bulk demand, Cashieru de C.E.R.O., No-s: 3-4 (1988), 119-123.

14. K. Usha, Eswari Prem and Ramanarayanan.R, "Stochastic Process in Time to vital Organs failure of Gestational Diabetic Person", Applied Mathematical Sciences, 5(10), 477-493.

\section{AUTHORS PROFILE}

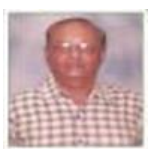

Dr.C.Mohan, Ph.D from veltech university, Chennai, 20 Nat/International papers published, he is active researcher in Markov Process.

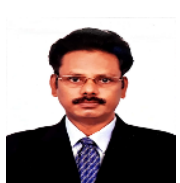

Dr. P.Selvaraju, his $\mathrm{Ph}, \mathrm{D}$ from anna university, Chennai, he published 100 of papers in Nat/International journals, area of research is graph theory, image processing, solar energy, gravitational energy, he is life member of ISTE, he is teaching in engineering college about three decades..

Dr.S.Shanmugan, he is $\mathrm{Ph} . \mathrm{D}$ holder, published around 50 Nat/International papers, received best referee awardee from Elsevier, he working in solar energy transmission using fuzzy logic, member of ISTE.

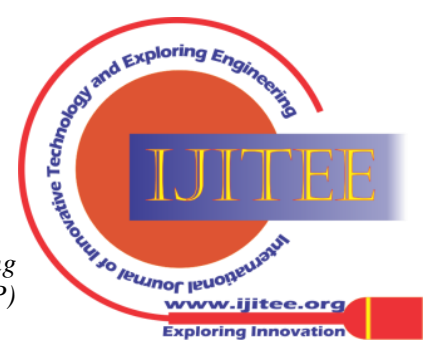

